\title{
Citral effect in male NMRI mice nonalcoholic steatosis model: assessing biochemical and histological parameters and PPARa gene expression
}

\author{
Maryam Vaezi $^{1}$, Parichehreh Yaghmaei ${ }^{*}$, Nasim Hayati-Roodbari ${ }^{1}$, Shiva Irani ${ }^{1}$, \\ Azadeh Ebrahim-Habibi ${ }^{2,3 *}$
}

\begin{abstract}
${ }^{1}$ Department of Biology, Science and Research Branch, Islamic Azad University, Tehran, Iran, ${ }^{2}$ Biosensor Research Center, Endocrinology and Metabolism Molecular-Cellular Sciences Institute, Tehran University of Medical Sciences, Tehran, Iran, ${ }^{3}$ Endocrinology and Metabolism Research Center, Tehran University of Medical Sciences, Tehran, Iran
\end{abstract}

\begin{abstract}
Citral is a small molecule present in various citrus species, with reported anti-hyperlipidemic and antiinflammation effects. Here, the effect of intraperitoneal (IP) administration of citral is evaluated in a mouse model of non-alcoholic steatosis. Male NMRI mice were divided into the following groups $(\mathrm{n}=$ 12): normal control group (NC) receiving a normal diet; high-fat emulsion group (HF) receiving high fat diet for four weeks; positive control group $(\mathrm{C}+)$ receiving $\mathrm{HF}$ diet for four weeks and then shifted to normal diet with IP-administered silymarin $(80 \mathrm{mg} / \mathrm{kg})$ for four weeks; sham group receiving HF diet for four weeks and then shifted to normal diet for four weeks; and EC1, EC2, and EC3 groups receiving HF diet for four weeks and then shifted to normal diet with IP-administered citral doses of 5, 10, and $20 \mathrm{mg} / \mathrm{kg}$, respectively. HF diet resulted in steatohepatitis with impaired lipid profile, high glucose levels and insulin resistance, impaired liver enzymes, antioxidants, adiponectin and leptin levels, decreased PPAR $\alpha$ level, and fibrosis in the liver tissue. Upon treatment with citral, improvement in condition was observed in a dose-dependent manner-both at histological level and in the serum of treated animals. and the PPAR $\alpha$ level was also increased.
\end{abstract}

Keywords: Citral effects. Lemonal. Liver disease. Silymarin

\section{INTRODUCTION}

Non-alcoholic fatty liver disease (NAFLD) is the most important cause of chronic liver diseases (Videla et al., 2006). It is considered as the hepatic manifestation of metabolic syndrome (MS) (Lonardo et al., 2005, Krawczyk, Bonfrate, Portincasa, 2010). NAFLD is defined as accumulation of fat in the liver in the absence of excessive drinking of alcohol. The condition can progress from simple non-alcoholic steatosis (NAS) to nonalcoholic steatohepatitis (NASH), and finally to hepatic fibrosis (Ahmed, 2015).

\footnotetext{
*Correspondence: P. Yaghmaei. Department of Biology, Science and Research Branch, Islamic Azad University, Tehran, Iran. Tel:+98 912 2010222. Fax: +98 21 22363520. E-mail: yaghmaei_p@srbiau.ac.ir

A. Ebrahim-Habibi. Biosensor Research Center, Endocrinology and Metabolism Molecular-Cellular Sciences Institute, Tehran University of Medical Sciences, Jalal-al-Ahmad Street, Chamran Highway, 1411713137, Tehran, Iran. Tel: +98 21 88220038. Fax: +9821 88220052. E-mail: aehabibi@sina.tums.ac.ir, azadehabibi@yahoo.fr
}

NAFLD is associated with metabolic risk factors such as obesity, diabetes mellitus, dyslipidemia, and oxidative stress (Krawczyk, Bonfrate, and Portincasa, 2010). In order to study this condition and find potential treatments, animal models of steatohepatitis, insulin resistance, and obesity are useful (Koteish, Diehl, 2002). Oxidative stress occurs when the balance between Reactive Oxygen Species (ROS) and antioxidant molecules is impaired (Seren et al., 2008). Hepatic overloading of FFA may cause oxidative stress (Chew, Park, 2004). ROS-induced oxidative stress is observed in obesity and NAFLD, in both humans and rodents (Aubert et al., 2011). In fact, ROS may act on lipid peroxidation of polyunsaturated fatty acids, resulting in the production of malondialdehyde (MDA). MDA has long-term adverse effects on liver cells (Day, 2006). In liver steatosis, increased levels of cytokines - such as tumor necrosis factor-alpha (TNF- $\alpha$ ) - are also observed (Zahran et al., 2013). Finally, histological changes indicative of this 
disorder occur in the perivenular regions of the liver parenchyma (Guicciardi et al., 2013).

Previous studies have shown that high caloric intake is an important factor frequently associated with NAFLD as well as other metabolic syndromes in humans. Hepatic steatosis may also develop when animals are fed $a d$ libitum with a high-fat diet (Zou et al., 2006). In addition, Peroxisome Proliferator-Activated Receptor Alpha (PPAR $\alpha$ ) gets markedLy decreased over high-fat (HF) intake. PPARs are important ligand-activated transcription factors involved in the regulation of nutrient homeostasis (Feige et al., 2006) and expressed in a variety of tissues and organs, such as liver, kidney, heart, and muscle. They can regulate energy homeostasis, stimulate gluconeogenesis and fatty acid catabolism, and are involved in the control of lipoprotein assembly (Rakhshandehroo et al., 2010). Some evidences showed that PPAR $\alpha$ is an important regulator of hepatic (mitochondrial and peroxisomal) beta-oxidation. PPAR $\alpha$ is markedLy decreased by HF intake (SouzaMello, 2015) and, thus, could be involved in controlling the disease state.

Citral, formed by enantiomers neral (cis) and geranial (trans), is the major aliphatic aldehyde monoterpene of Lippia alba and Cymbopogon citratus. It is found in all citrus species. Lemongrass (Cymbopogon citratus), an evergreen plant growing in Asia, is an important source of this oil. Citral has antimicrobial, anti-inflammatory (Martins et al., 2017) as well as anti-hyperlidemic effects (Najafian et al., 2011). It is obtained at low cost and shows no particular toxicity at low doses (Dieter et al., 1993). As a retinaldehyde dehydrogeanse inhibitor, it is demonstrated that citral administration can significantly lower body weight gain and abdominal fat mass in rats on a high-energy diet. while decreasing serum insulin levels and improves glucose tolerance (Modak, Mukhopadhaya, 2011). Retinaldehyde can activate PPAR receptors, leading to an increase in serum adiponectin levels, which has beneficial effects in regulating both the liver and muscle metabolism (Yang et al., 2005). Overall, based on these previous studies, citral seems to be a good candidate for improving or decreasing fatty liver injuries. We have, thus, investigated the effect of citral compounds on biochemical, histological indicators, and PPAR $\alpha$ gene expression, induced by high caloric diet in male NMRI mice.

\section{MATERIAL AND METHODS}

\section{Material}

Citral was obtained from Sigma-Aldrich, St. Louis, MO, USA. Commercial kits were used for the measurement of high density lipoprotein cholesterol (HDL-C), low density lipoprotein cholesterol (LDL-C), total cholesterol, triglycerides (TG), glucose, alanine aminotransferase (ALT), aspartate aminotransferase (AST), and alkaline amino transferase (ALP). These were purchased from the ZistChimi Chemical Company, Tehran, Iran. Serum adiponectin, leptin, and the insulin measurement kits were purchased from Yanaihara Institute Inc. Catalog No. YII-YK052-EX, JAPAN. The homeostasis model assessment (HOMA) formula was used as an insulin resistance index: HOMA = fasting serum insulin $(\mathrm{mU} / \mathrm{L}) \times$ fasting plasma glucose $(\mathrm{mM}) / 22.5$ (Barnea et al., 2006).

\section{Preparation of fat emulsion}

High-fat emulsion diet was prepared with the following components: Cholesterol (> 95\% [CG] Sigma), Tween 80 , sucrose, sodium deoxycholate and propylene glycol (Sigma-Aldrich), total milk powder (Aptamil), multivitamin, and carbohydrates. The composition of this emulsion is shown in Table I. In this emulsion, total milk powder provided proteins. However, carbohydrates source was sucrose, fat was obtained by corn oil, and the diet was supplemented with a vitamin and mineral mixture. This emulsion was stored at $4{ }^{\circ} \mathrm{C}$ and then heated in a $42{ }^{\circ} \mathrm{C}$ water bath, and fully mixed before use.

TABLE I - Composition and caloric content of the high-fat emulsion diet

\begin{tabular}{lc}
\hline Components of high fat emulsion & Amount \\
\hline Corn oil $(\mathrm{g})$ & 178 \\
Saccharose $(\mathrm{g})$ & 13.37 \\
Total milk powder $(\mathrm{g})$ & $7.13 / 2$ \\
Cholestrol $(\mathrm{g})$ & 8.92 \\
Sodium deoxycholate(g) & 0.89 \\
Tween 80 (g) & 3.25 \\
Propylene glycol(g) & 2.78 \\
Multi Vitamin & 0.22 \\
Cooking Salt $(\mathrm{g})$ & 0.89 \\
Mineral mixture $(\mathrm{g})$ & 0.13 \\
Distilled water $(\mathrm{mL})$ & 40.1 \\
\hline
\end{tabular}

\section{Animals and treatment}

Male NMRI mice (6 weeks old and 25-30 g) were supplied by Razi Vaccine and Serum Institute, Karaj, Iran. They were kept in cages in an animal's room under 
standard conditions (temperature $22 \pm 1^{\circ} \mathrm{C}$ and a $12-\mathrm{h}$ light-dark cycle). They were given ad libitum access to standard pellet and water.

After a week of adaption, the animals were weighed and divided into the following groups $(\mathrm{n}=12)$ :

- $\quad$ Normal control group (NC group) received normal diet.

- High-fat emulsion group (HF group) received high fat diet, which was composed of normal diet supplemented with additional high-fat emulsion (Table I) for four weeks (Zou et al., 2006).

- $\quad$ Positive control group $(\mathrm{C}+)$ received high-fat emulsion for four weeks and was then shifted to $\mathrm{NC}$ with silymarin $(80 \mathrm{mg} / \mathrm{kg})$ administered by intraperitoneal injection(IP) for four weeks.

- Sham group received high-fat emulsion for four weeks and was then shifted to normal diet for four weeks.

- $\quad$ EC1 group received high-fat emulsion for four weeks and was then shifted to NC with citral $(5 \mathrm{mg} / \mathrm{kg})$, administered by intraperitoneal injection (IP) for four weeks.

- $\quad$ EC2 group received high-fat emulsion for four weeks and was then shifted to NC with citral $(10 \mathrm{mg} / \mathrm{kg})$, administered by intraperitoneal injection (IP) for four weeks.

- $\quad$ EC3 group received high-fat emulsion for four weeks and was then shifted to NC with citral $(20 \mathrm{mg} / \mathrm{kg})$, administered by intraperitoneal injection (IP) for four weeks.

- Protective group (PC) received high-fat emulsion and citral $20 \mathrm{mg} / \mathrm{kg}$ simultaneously for four weeks.

All NMRI mice were fed with standard rodent food and water. The model mice received high-fat emulsion via oral gavage every day for four weeks. The $\mathrm{NC}$ group was given equal volumes of saline via daily gavage (Zou et al., 2006). At the end of the treatment with high-fat emulsion, animals from the HF group were selected randomLy. Their livers were removed under diethyl ether anesthesia. Histopathological examination was conducted on the liver tissue and fatty cell formation was confirmed. Treatment with citral and silymarin (test and positive control groups) continued according to the experimental protocol for four weeks by IP injection. During the experimental period, all animals were weighed every week. The experimental protocol was performed in accordance with the Guide for the Care and Use of Laboratory Animals (Institute of Laboratory Animal Resources, 1996). Moreover, the University's Animal Ethics Committee approved the protocol.

\section{Histological and biochemical assessment}

At the end of the experiment, animals were made to fast (12 hours without food) and then weighed. NMRI mice were anesthetized by inhalation of diethyl ether. Terminal blood sample withdrawal from cardiac ventricles was conducted with the help of $2.5 \mathrm{~mL}$ syringes. Liver tissues were removed and fixed in a formalin buffer solution $(10 \%)$ in order to do histological assessment. After embedding the tissues in paraffin, cross sections of $5 \mu \mathrm{m}$ were prepared according to the routine protocols. Liver sections were stained with hematoxylin and eosin (H\&E) and Masson's Trichrome (MT). The slides were examined by light microscopy. Liver tissue samples were also used to measure antioxidant enzyme activities and other biochemical parameters, such as hepatic SOD and malondialdehyde (MDA) activities. Tissue samples were removed, weighed, and then homogenized $(1: 3 \mathrm{w} / \mathrm{v})$ in phosphate saline buffer $(\mathrm{pH}=7.4)$. Homogenate samples were then sonicated for 1.5 minutes and bursts for 30 seconds. All the procedures were performed at $0-4{ }^{\circ} \mathrm{C}$. Homogenate samples were finally centrifuged at $22,000 \mathrm{~g}$ for 17 minutes at $4{ }^{\circ} \mathrm{C}$ in a microcentrifuge. The supernatant was frozen at $-40{ }^{\circ} \mathrm{C}$ till the time of assay. Visceral white adipose tissue was taken and stored at $-70{ }^{\circ} \mathrm{C}$ for molecular analysis. The serum levels of HDL-C, LDL-C, TG (Marklund, Marklund, 1974; Asadi et al., 2008), ALP, AST, and ALT, Ferric Reducing Antioxidant Power (FRAP), catalase, total protein, insulin, glucose TNF- $\alpha$, adiponectin, and leptin were measured using commercial kits.

\section{RNA isolation and cDNA synthesis}

Total RNA was isolated from whole mice liver tissue by using a commercial RNA isolation kit (Roche Diagnostics GmbH Roche Applied Science 68298 Mannheim, Germany). The cells were suspended in $200 \mu \mathrm{L}$ PBS, to which $400 \mu 1$ Lysis/Binding Buffer was added and mixed for 15 seconds. After transferring it to a high pure filter tube, centrifugation was done for 15 seconds at $8,000 \times g$. Flowthrough was discarded and $100 \mu \mathrm{L}$ DNase was added, incubating the mixture for 15 minutes at $25^{\circ} \mathrm{C}$. Washing buffer was used twice, followed by centrifugation, and RNA was eluted by $100 \mu$ L Elution Buffer. The purified RNA can be used directly in RT-PCR or stored at $-80^{\circ} \mathrm{C}$ for later analysis.

The primer sequences for PPAR $\alpha$ and HPRT (used as housekeeping gene) were obtained from Yekta tajhize Azma website. Specific primers were designed by the primer express program (Table II). 
TABLE II - Sequences of probe and oligonucleotides used in real-time PCR analysis

\begin{tabular}{ll}
\hline Gene & \multicolumn{1}{c}{ Sequence } \\
\hline PPAR $\alpha$ & 5'GGGGAACTTAGAGGAGAGCCAAG3' \\
(Forward) & \\
PPAR $\alpha$ & 5'CGCTAAGCTGTGATGACAACG3' \\
(Reverse) & \\
HPRT & 5'TCAGACTGAAGAGCTACTGTAATGATCAG3' \\
(Forward) & \\
HPRT & 5'TCAACAATCAAGACATTCTTTCCAG3' \\
(Reverse) & \\
\hline
\end{tabular}

\section{Statistical analysis}

The data was analyzed using SPSS statistical software and mean \pm SEM (standard error of mean), followed by Turkey's post hoc test. $\mathrm{P}<0.05$ was set as a statistical significance.

\section{RESULTS}

\section{Body weight}

After four weeks, weights of the mice of different groups were significantly different, as compared with the control group (Table III). Removing high fat diet from Sham group for four weeks caused a decrease in body weight, as compared with the HF group $(\mathrm{P}<0.001)$. Between the experimental groups, the body weight of EC2 (citral $10 \mathrm{mg} / \mathrm{kg}$ ), EC3 (citral 20mg/kg), and PC (protective group; citral $20 \mathrm{mg} / \mathrm{kg}$, with high fat diet simultaneously) were significantly reduced in comparison to HF $(\mathrm{P}<0.001)$. Furthermore, body weight in EC3 group was significantly lower than EC1 and EC2 groups $(\mathrm{P}<0.001)$. These results demonstrated that the highest used dose of citral was more efficient in body weight reduction in the HF group.

\section{Biochemical parameters}

Measured biochemical parameters including cholesterol, glucose, liver enzymes, and insulin are shown in Table IV. The serum levels of cholesterol, TG, LDL, VLDL, total lipid, phospholipid, and liver enzymes in the HF group showed a significant increase in comparison with the control group $(\mathrm{P}<0.001)$. On the other hand, the levels of cholesterol and TG in treated groups significantly decreased, as compared with the HF and Sham groups $(\mathrm{P}<0.001)$. Phospholipid levels decreased in EC3 and PC groups, as compared with the HF and Sham groups $(\mathrm{P}<0.001)$.

The HDL-C levels were markedLy reduced in the HF group and increased in EC3 group, and to a lesser extent in the Silymarin group (Table IV). The serum levels of LDL-C in HF group significantly increased, as compared with the control group. However, in EC3 group, significant reduction was observed, as compared with HF and Sham groups $(\mathrm{P}<0.001)$.

The levels of the hepatic enzymes ALP, AST, and ALT were increased in HF group, as compared with the control group $(\mathrm{P}<0.001)$. Treatment with citral $(20 \mathrm{mg} / \mathrm{kg})$ caused a significant decrease in all liver enzyme levels, as compared with the HF and Sham group $(\mathrm{P}<0.001)$. A similar result was seen for Silymarin (Table IV). Glucose, serum insulin levels, and insulin resistance significantly increased in the HF group, as compared with the control group $(\mathrm{P}<0.001)$. Citral $(20 \mathrm{mg} / \mathrm{kg})$ administration affected all these factors and caused a significant decrease, in comparison to HF and Sham groups. This phenomenon was similar to that of Silymarin (Table IV).

TNF- $\alpha$ levels markedLy increased in the HF group, as compared with the Control group. However, it significantly decreased in the citral treated groups (both EC3 \& PC), as compared with the HF and Sham groups $(\mathrm{P}<0.001)$ as well as the $\mathrm{C}+$ group. The liver enzymes superoxide dismutase (SOD), malonyledialdehyde (MDA), and catalase were affected by high fat emulsion in the HF group, as compared with the Control group (Table IV). The serum levels of SOD and catalase showed a significant increase in EC3, PC, and $\mathrm{C}+$ groups, as compared with the HF and Sham groups, while MDA levels significantly decreased (Table IV).

TABLE III - Comparison of body weights at the end of the experiment

\begin{tabular}{|c|c|c|c|c|c|c|c|c|}
\hline Group & $\mathrm{NC}$ & HF & $\mathrm{C}+$ & Sham & Ec1 & Ec2 & Ec3 & Pc \\
\hline Initial weight & $27 \pm 1$ & $24 \pm 0.5$ & $25 \pm 0.7$ & $27 \pm 0.4$ & $26 \pm 0.3$ & $25.3 \pm 0.3$ & $25.6 \pm 0.4$ & $26.8 \pm 0.3$ \\
\hline After 4 weeks & $40.5 \pm 0.4$ & $\begin{array}{c}49.5 \pm 0.3 \\
* * *\end{array}$ & $\begin{array}{c}37 \pm 0.6 \\
\$ \$ \$\end{array}$ & $\begin{array}{c}42.6 \pm 1 \\
\$ \$ \$\end{array}$ & $\begin{array}{c}37.6 \pm 0.6 \\
\# \# \# \$ \$\end{array}$ & $\begin{array}{c}37 \pm 0.7 \\
\$ \$ \$ \# \# \#\end{array}$ & $\begin{array}{l}30.9 \pm 0.9 \\
\$ \$ \$ \# \# \#\end{array}$ & $\begin{array}{c}38.4 \pm 0.5 \\
\$ \$ \$ \# \#\end{array}$ \\
\hline
\end{tabular}

*** $\mathrm{p}<0.001$ compared with control, $\$ \$ \$ \mathrm{p}<0.001$ compared with $\mathrm{HF}$, \#\#<0.01 compared with sham, \#\#\# $<<0.001$ compared with Sham 
TABLE IV - Effect of citral on biochemical indices and antioxidant enzymes in mice treated with high fat emulsion. Data are expressed as mean \pm SEM. $* * * p<0.001$ compared with $\mathrm{NC}$ (Normal control), $\$ \$ \mathrm{p}<0.001$ compared with HF, $® \circledR \circledR \mathrm{p}<0.001$ compared with sham, $\$ \$ p<0.01$ compared with $\mathrm{HF},{ }^{\circledR} \mathbb{R}<<0.01$ compared with sham, $\$ \mathrm{p}<0.05$ compared with $\mathrm{HF}$ (high fat), ${ }^{\circledR} \mathrm{p}<0.05$ compared with sham.

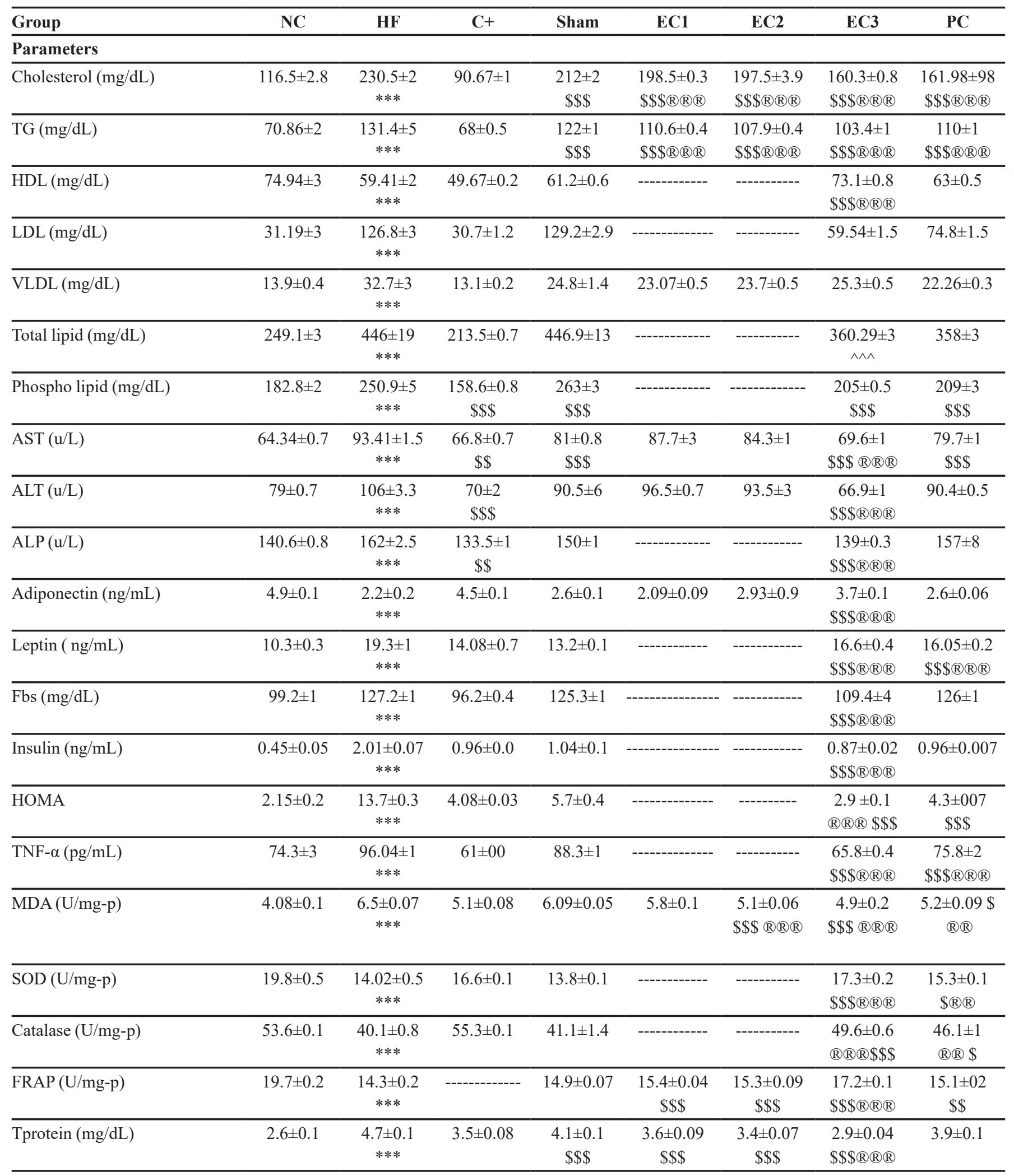


Ferric Reduction Antioxidant Power (FRAP) levels were reduced in the HF group, as compared with the Control group. However, it increased in all the treated groups, as compared with the HF group. The differences in FRAP levels between EC3 and Sham groups were remarkable (Table IV). Serum adiponectin levels decreased in the HF and Sham groups and significantly increased in $\mathrm{C}+$ and $\mathrm{EC} 3$ groups. Treatment with high fat emulsion resulted in a significant increase of leptin levels in the HF group. The consumption of silymarin and citral $(20 \mathrm{mg} / \mathrm{kg})$ could decrease leptin levels, as compared with the HF and Sham groups (Table IV).

\section{Gene expression}

Percentages of PPAR $\alpha$ gene expression evaluated in liver tissue are showed in Figure 1. The highest percentage of increase in PPAR $\alpha$ gene expression was observed in EC3 group, as compared with control (Figure 1). On the other hand, a significant increase $(30 \pm 3 \%)$ in EC3 group was observed, as compared with the HF and Sham group $(24 \pm 1 \%)(\mathrm{P}<0.001)$.

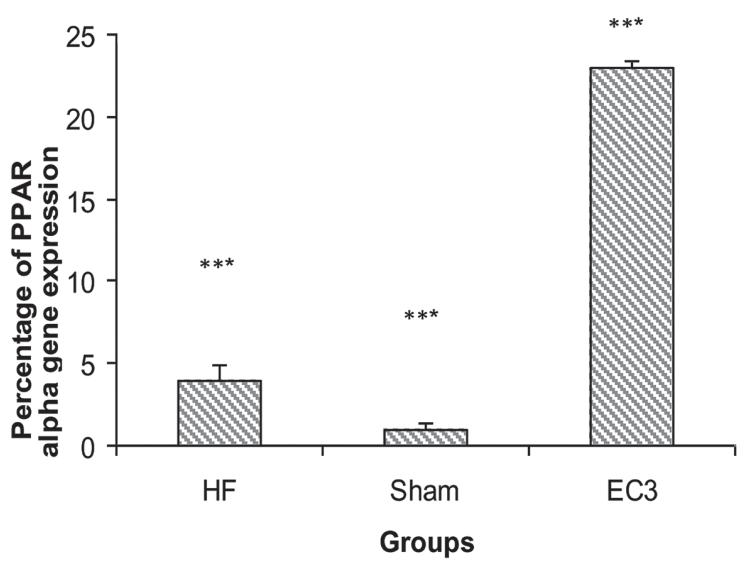

FIGURE 1 - Comparison of PPAR $\alpha$ gene expression between HF, Sham and EC3 with control. ***p $<0.001$ compared with control.

\section{Histopathological Evaluation}

Histological changes occurring in NAFLD can affect the liver parenchyma, as observed in liver samples stained with Hematoxyline \& Eosine (Figure 2A, C, E, G, I, K, $\mathrm{M}, \mathrm{O}$ ) and Masson's trichrome (Figure 2B, D, F, H, J, L, $\mathrm{N}, \mathrm{P})$. In the Control group, normal hepatic cells were observed after four weeks (Figure 2A \& B). However, the livers of the HF group were found grossly larger, as compared with the $\mathrm{NC}$ group. Liver steatosis was showed as a change in liver fatty cells in this group (indicated with arrows in Figure 2). There was marked perivenular fibrosis in the HF group, which is observed in Masson's trichrome staining (arrows in Figure 2D). Fibrosis is highlighted in blue by this stain.

In the group that received silymarin after high fat emulsion, steatosis was alleviated (Figure $2 \mathrm{G} \& \mathrm{H}$ ). A similar condition to the control group was observed. In the liver sections of the Sham group, mild fibrosis was observed around the portal tract (Figure $2 \mathrm{H}$ ).

In the groups treated with citral $(5,10$, and $20 \mathrm{mg} / \mathrm{kg}$ ), depending on the dose, fatty content change in hepatocytes was affected at accordingly different extent (Figure $2 \mathrm{M}$ ). In the $20 \mathrm{mg} / \mathrm{kg}$ group, liver steatosis was no more observed.

\section{DISCUSSION}

In the current study, four weeks of treatment with high fat emulsion was used to induce NAFLD in NMRI mice. The histological changes occurring in NAFLD predominantly affected the liver parenchyma and fat changes were mostly macrovesicular in nature. At the end of this period, fat accumulation in the liver was clearly observed by hematoxylin and eosin (Figure 2C).

Masson's trichorome staining showed fibrosis around the hepatic parenchyma (Figure 2D).

Animals were then treated with citral for four weeks. The effects of this compound were assessed using the following parameters: body weight, lipid profiles, antioxidant enzymes levels, serum levels of adiponectin and leptin, glucose and insulin levels, liver tissue histology, and PPAR $\alpha$ gene expression in liver tissue. Silymarin, which consists of polyphenols and is derived from the milk thistle plant, was used as a positive control. This was because it is currently considered to have favorable effect in the treatment of NAFLD (Del Ben et al., 2017).

High fat emulsion leads to an increase in body weight in rodents when used for six weeks (Zou et al., 2006). Our results were in accordance with this study (although with a difference in the period of treatment). Our study showed that HF emulsion caused a significant increase in the body weight of mice after four weeks, as compared with the Control group. The results of the experimental groups (compared with Sham group) showed that treatment with citral, especially citral at a $20 \mathrm{mg} / \mathrm{kg}$, caused a reduction in body weight. This seems to have a better effect, as compared with silymarin. Similar findings have been reported in rodent models of diabetes (Najafian et al., 2011) and obesity (Modak, Mukhopadhaya, 2011), where citral is suggested to act via an anti-appetite effect or increase in energy expenditure. 

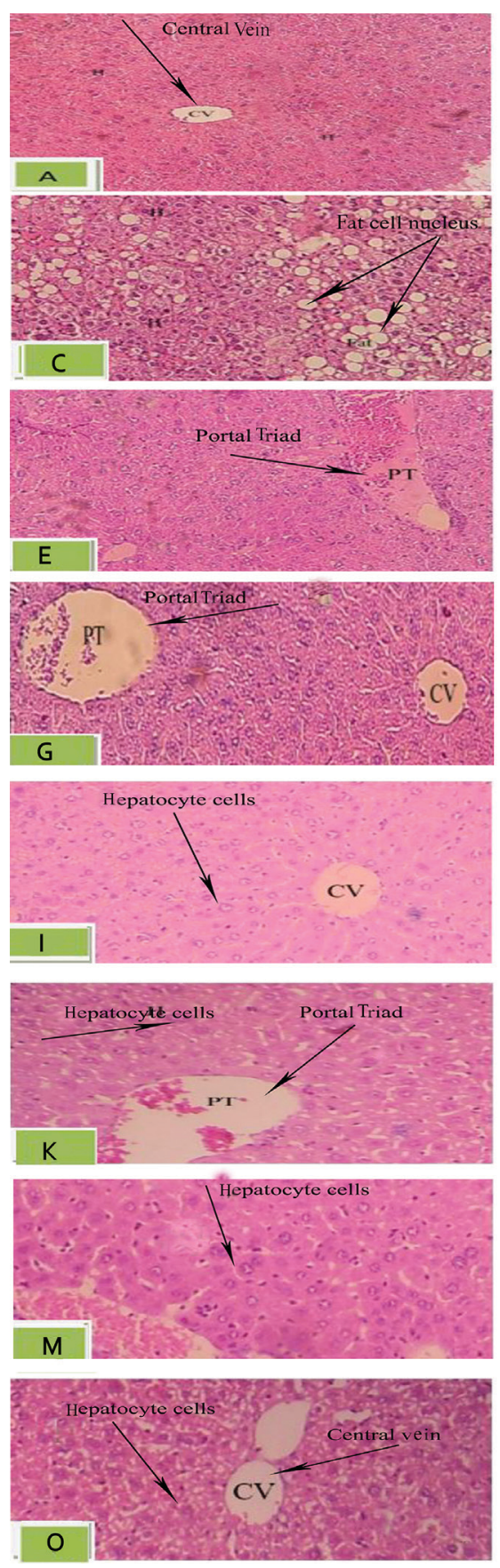
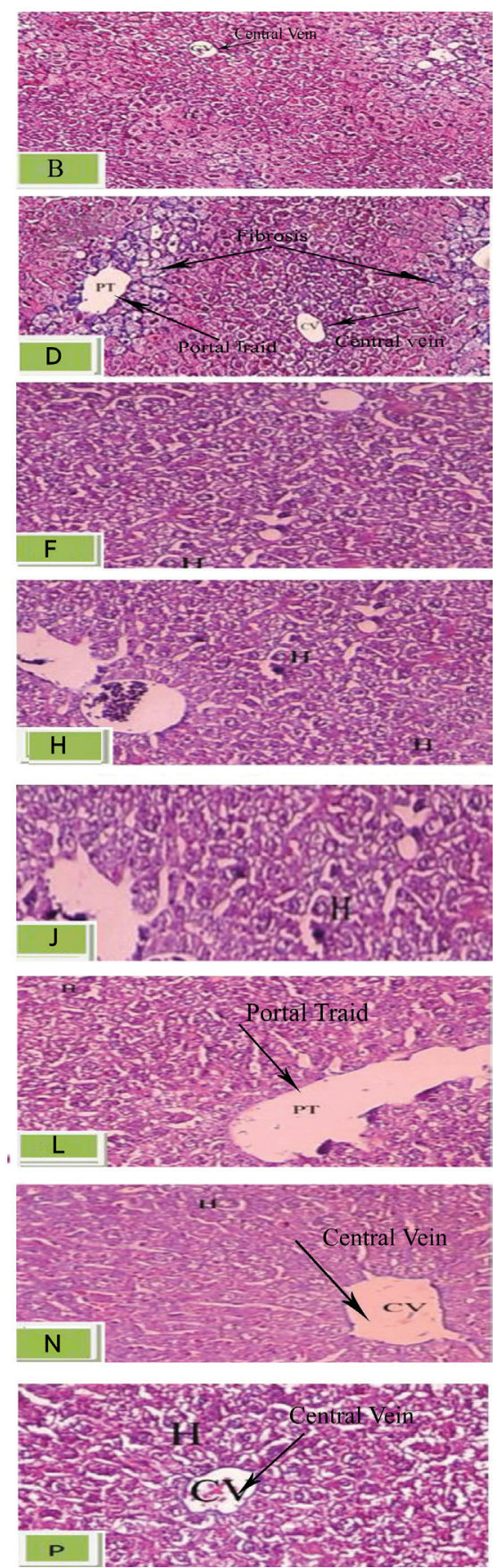

FIGURE 2 - Histopathological effects of citral on liver tissue in HF-fed mice (magnification:100). Liver tissue sections assessed by Hematoxyline \& Eosin (H\&E- A,C,E,G,I,K,M) and Masson's trichorome (MT- B,D,F,H,J,L,N) perivenular fibrosis was observed in Masson's trichrome, arrows in fig $2 \mathrm{D}$ show the parts of the liver tissue that have been altered to blue color due to fibrosis. Fatty change in hepatocytes (HF) group was observed with Hematoxyline \& Eosine, in Fig 2 C. The arrows show the fat cells in liver tissue. In other images of Hematoxyline \& Eosine staining arrows show three different parts of liver tissue, which include central vein $(\mathrm{CV})$, portal triad $(\mathrm{PT})$ and hepatocyte cells $(\mathrm{H})$. A: Hematoxyline \& Eosin for control group; B: Masson's trichorome for control group; C: Hematoxyline \& Eosin for HF group; D: Masson's trichorome for HF group; E: Hematoxyline \& Eosin for Sh group; F: Masson's trichorome for Sh group; G: Hematoxyline \& Eosin for C+ (silymarin) group; H: Masson's trichorome for $\mathrm{C}+$ (silymarin) group; I: Hematoxyline \& Eosin for EC1 ( citral $5 \mathrm{mg} / \mathrm{kg}$ ) group; J: Masson's trichorome for EC1 (citral $5 \mathrm{mg} / \mathrm{kg}$ ) group; K: Hematoxyline \& Eosin for EC2 (citral $10 \mathrm{mg} / \mathrm{kg}$ ) group; L: Masson's trichorome for EC2(citral $10 \mathrm{mg} / \mathrm{kg}$ ) group; M: Hematoxyline \& Eosin for EC3(citral $20 \mathrm{mg} / \mathrm{kg}$ ) group; N: Masson's trichorome for EC3(citral $20 \mathrm{mg} / \mathrm{kg}$ ) group; O: Hematoxyline \& Eosin for PC (protective) group; P: Masson's trichorome for PC (protective) group. Abbreviation: CV(central vein), PT(portal triad) and $\mathrm{H}$ (hepatocyte cells). 
Increasing levels of lipid profiles indices cholesterol, TG, LDL-C, total lipid, phospholipid, and reduction of HDL-C levels are observed in obesity (Asadi, Shahriari, Chahardah-Cheric, 2010). They are risk factors associated with oxidative stress that lead to hepatic metabolic disorder (Saravanan et al., 2014). The liver has an important role in lipid metabolism. Imbalance between production and consumption of lipids causes hepatic steatosis (Stanton et al., 2011).

The measurement of serum ALP, AST, and ALT provides an indication of liver function (Hall, Cash, 2012). At the end of the experimental period, plasma levels of these parameters increased in the HF group, which were modulated by citral administration. At a high dose, the therapeutic effect may be exerted throughout the antioxidant activity (Yang et al., 2013). Previous studies have showed that high fat diet results in increased oxidative stress and reduces free radical scavenger enzymes, which finally cause cell damage (Sreekumar et al., 2002). Hepatic concentration of MDA enzyme (products of lipid proxidation) increases and the SOD activity is reduced (Zou et al., 2006). Antioxidant enzymes, like SOD and catalase, protect cells from damage with the help of breakdown free radicals. When SOD can break down anion superoxide $\left(\mathrm{O}_{2}^{-}\right)$into hydrogen peroxide (H2O2), catalase converts it immediately to water. The positive effects of citral administration $(20 \mathrm{mg} / \mathrm{kg}$ ) on MDA, SOD, and catalase are in accordance with a previous study. This suggests lemongrass inhibition of free radical attacks on biomembrane (Ojo et al., 2006). Citral can inhibit the process of increase in ROS (Reactive Oxygen Species) and NO production. In this regard, citral compound may have a therapeutic effect on hepatic diseases through the inhibition of oxidative stress (Yang et al., 2013). Interestingly, silymarin, which attenuates liver fibrosis associated problems, has also been reported to act as an antioxidant (Del Ben et al., 2017).

Insulin resistance exacerbates the abnormalities in hepatic fat metabolism. With insulin resistance (as a strong predictor of NAFLD), the combination of increase in plasma concentrations of glucose and fatty acids promotes hepatic fatty acid synthesis and impairment of $\beta$-oxidation. This further leads to hepatic steatosis (Zammit, 2002). The finding of this study showed that feeding mice with high fat emulsion caused a significant increase in the serum levels of glucose, insulin, and index of insulin resistance (HOMA), in comparison with the control group. In fact, the reduction of insulin levels was accompanied with improved glucose tolerance. Previous reports showed that citral has an insulin-sensitizing and alpha-amylase inhibitory effect (Zammit, 2002; Najafian et al., 2011).
Furthermore, reduction in TG and cholesterol after use of citral can be attributed to better utilization of glucose. This was reflected by a decrease in blood glucose and increased insulin levels and, therefore, depressed mobilization of fat (Lonardo et al., 2005).

Decreased levels of adiponectin in HF group, as compared with the Control group, were increased upon citral administration. In fact, adiponectin can prevent the accumulation of lipids by increasing the beta oxidation of free fatty acids in hepatocytes (Ma et al., 2002). On the other hand, both leptin and adiponectin play an important role in energy balance. Adiponectin can modulate glucose and fatty acid metabolism. Leptin is a mediator of energy balance, suppressing food intake, and thereby inducing weight loss (Klok, Jakobsdottir, Drent, 2007). Furthermore, hyperleptinemia can help hepatic statosis due to changes in the accumulation of hepatic fat (Chitturi et al., 2002). Changes in the levels of adipokines can improve insulin resistance, obesity, and fatty liver (Ghantous et al., 2015). Similar to other reports, the current study showed that high fat emulsion increased serum leptin and decreased adiponectin levels in animals (Barnea et al., 2006), and citral can affect both parameters. In the current study, overall comparison of citral and sylimarin on the above-discussed biochemical parameters showed that the higher administered dose of citral had comparable effect on many parameters - including enzyme liver and cytokines. Although it had a lower effect on some of the lipid profile indicators, it acted better on HDL, weight, and HOMA index.

PPAR $\alpha$ is a transcriptional factor activated by ligands and can regulate the expression of genes involved in lipid oxidation pathway. Examples include genes of carnitine palmitoyl transferase 1 . This has a role in fatty acids transporting into mitochondria and lipoprotein lipase, which is related to VLDL triglyceride lipolysis (Ziamajidi et al., 2013). Overall, PPAR $\alpha$ has an important role in fatty acid oxidation, oxidative stress, energy balance, and lipid metabolism. In fact, a decrease in the expression of PPAR $\alpha$ causes impaired fatty acids $\beta$-oxidation. This may result in imbalance of lipid metabolism and lead to lipid accumulation in the case of induced lipogenic transcription (Reddy, 2001). Our results show, in accordance to other studies, a marked decrease in PPAR $\alpha$ over high-fat (HF) intake (Feige et al., 2006). Previous reports indicated that citral could activate PPAR $\alpha$ expression by inducing mRNA expression of the PPAR $\alpha$ responsive carnitine palmitoyltransferase 1 gene (Katsukawa et al., 2010). Accordingly, we observed that a $20 \mathrm{mg} / \mathrm{kg}$ dose of citral considerably increased PPAR $\alpha$ gene expression, as compared with the HF and Sham group. 
Hepatocytes and kupffer cells secrete TNF- $\alpha$ directly in the liver, while abdominal fat can also produce it. Several studies reported that TNF- $\alpha$ played a key role in developing NAFLD in human and animals. TNF- $\alpha$ is associated with insulin resistance and animals studies showed that the inhibition of TNF-alpha improved NAFLD (Chu et al., 2006). Similar to previous studies, we observed that high-fat emulsion treatment for four weeks significantly increased TNF- $\alpha$ levels in the HF group. On the other hand, citral treatment caused reduction in TNF- $\alpha$ levels. Citral can reportedLy inhibit inflammatory factors TNF- $\alpha$ and nitric oxide (NO) production. NF- $\kappa B$, as a transcription factor, was a target for this anti-inflammatory effect and could be affected by citral (Song et al., 2016).

Finally, histopathological assessment of liver section revealed that treatment with citral caused a dosedependent decrease of steatosis and fibrosis. Overall, citral, especially at a dose of $20 \mathrm{mg} / \mathrm{kg}$, prevented lipid deposition (Figure 2M). On the other hand, Masson's trichorome staining showed that citral at this dose had counteracted liver fibrosis. Liver fibrosis (marked with arrows in Figure 2D) was eliminated by citral $20 \mathrm{mg} / \mathrm{kg}$ administration (Figure $2 \mathrm{~N}$ ).

Based on the above results, we suggested that citral could modify NAFLD through improved activity of antioxidant enzymes, inhibition of inflammatory cytokine, and an increase of PPAR $\alpha$ gene expression. The overall effect of citral was comparable to silymarin, with better effect on some parameters. Due to the limited options available for NAFLD treatment and the need for a greater body of data on potentially effective compounds, citral could be proposed as an additional possibility in this regard.

\section{CONCLUSION}

Our results indicated that the administration of citral could control the harmful effects of NAFLD disease. This effect was exerted by up regulation of adiponectin, reduction of serum leptin levels, modulation of lipid profile, and increase of anti-oxidant enzyme levels. The effects of citral were notable and further development of this compound could potentially result into an effective therapeutic improvement of NAFLD.

\section{ACKNOWLEDGMENTS}

This study was performed in the Laboratory Complex of the Science and Research Branch of Azad University.

\section{COMPETING INTERESTS}

All authors declared they have no conflict of interests.

\section{REFERENCES}

Ahmed M. Non-alcoholic fatty liver disease in 2015. World J Hepatol. 2015;7(11):1450-9.

Asadi F, Shahriari A, Pourkabir M, Maclaren R. Short-and long-term effects of corn oil on serum lipid and lipoprotein and visceral abdominal fat pad parameters of rats. J Food Lipids. 2008;15(1):68-80.

Asadi F, Shahriari A, Chahardah-Cheric M. Effect of long-term optional ingestion of canola oil, grape seed oil, corn oil and yogurt butter on serum, muscle and liver cholesterol status in rats. Food Chem Toxicol. 2010;48(8):2454-2457.

Aubert J, Begriche K, Knockaert L, Robin M-A, Fromenty B. Increased expression of cytochrome P450 2E1 in nonalcoholic fatty liver disease: mechanisms and pathophysiological role. Clin Res Hepatol Gastroenterol. 2011;35(10):630-637.

Barnea M, Shamay A, Stark AH, Madar Z. A high-fat diet has a tissue-specific effect on adiponectin and related enzyme expression. Obesity. 2006;14(12):2145-2153.

Chew BP, Park JS. Carotenoid action on the immune response. J Nutr. 2004;134(1):257S-261S.

Chitturi S, Abeygunasekera S, Farrell GC, Holmes-Walker J, Hui JM, Fung C, et al. NASH and insulin resistance: insulin hypersecretion and specific association with the insulin resistance syndrome. Hepatology. 2002;35(2):373-379.

Chu C-J, Lu R-H, Wang S-S, Chang F-Y, Wu S-L, Lu C-L, et al. Risk factors associated with non-alcoholic fatty liver disease in Chinese patients and the role of tumor necrosis factor-alpha. Hepato-gastroenterology. 2006;54(79):2099-2102.

Day CP. From fat to inflammation. Gastroenterology. 2006;130(1):207-210.

Del Ben M, Polimeni L, Baratta F, Pastori D, Angelico F. The role of nutraceuticals for the treatment of non-alcoholic fatty liver disease. Br J Clin Pharmacol. 2017;83(1):88-95. 
Dieter M, Goehl T, Jameson C, Elwell M, Hildebrandt P, Yuan J. Comparison of the toxicity of citral in F344 rats and B6C3F1 mice when administered by microencapsulation in feed or by corn-oil gavage. Food Chem Toxicol. 1993;31(7):463-474.

Feige JN, Gelman L, Michalik L, Desvergne B, Wahli W. From molecular action to physiological outputs: peroxisome proliferator-activated receptors are nuclear receptors at the crossroads of key cellular functions. Prog Lipid Res. 2006;45(2):120-159.

Ghantous C, Azrak Z, Hanache S, Abou-Kheir W, Zeidan A. Differential role of leptin and adiponectin in cardiovascular system. Int J Endocrinol. 2015;2015:534320.

Guicciardi ME, Malhi H, Mott JL, Gores GJ. Apoptosis and necrosis in the liver. Compr Physiol. 2013;3(2):977-1010.

Hall P, Cash J. What is the real function of the liver 'function'tests. Ulster Med J. 2012;81(1):30-36.

Institute of Laboratory Animal Resources, $1996<<$ insert the reference $>>$

Katsukawa M, Nakata R, Takizawa Y, Hori K, Takahashi S, Inoue $\mathrm{H}$. Citral, a component of lemongrass oil, activates PPAR $\alpha$ and $\gamma$ and suppresses COX-2 expression. Biochim Biophys Acta. 2010;1801(11):1214-1220.

Klok M, Jakobsdottir S, Drent M. The role of leptin and ghrelin in the regulation of food intake and body weight in humans: a review. Obes Rev. 2007;8(1):21-34.

Koteish A, Diehl AM. Animal models of steatohepatitis. Best Pract Res Clin Gastroenterol. 2002;16(5):679-690.

Krawczyk M, Bonfrate L, Portincasa P. Nonalcoholic fatty liver disease. Best Pract Res Clin Gastroenterol. 2010;24(5):695-708.

Lonardo A, Lombardini S, Ricchi M, Scaglioni F, Loria P. Hepatic steatosis and insulin resistance. Aliment Pharmacol Ther. 2005;22(s2):64-70.

Ma K, Cabrero A, Saha PK, Kojima H, Li L, Chang BH$\mathrm{J}$, et al. Increased $\beta$-oxidation but no insulin resistance or glucose intolerance in mice lacking adiponectin. J Biol Chem. 2002;277(38):34658-34661.

Marklund S, Marklund G. Involvement of the superoxide anion radical in the autoxidation of pyrogallol and a convenient assay for superoxide dismutase. Eur J Biochem. 1974;47(3):469-474.
Martins HB, Selis NDN, Nascimento FS, Carvalho SPD, Gusmão LDO, Nascimento JDS, et al. Anti-Inflammatory Activity of the Essential Oil Citral in Experimental Infection with Staphylococcus aureus in a Model Air Pouch. Evid Based Complement Alternat Med. 2017;2017:2505610.

Modak T, Mukhopadhaya A. Effects of citral, a naturally occurring antiadipogenic molecule, on an energy-intense diet model of obesity. Indian J Pharmacol. 2011;43(3):300-5.

Najafian M, Ebrahim-Habibi A, Yaghmaei P, Parivar K, Larijani B. Citral as a potential antihyperlipidemic medicine in diabetes: a study on streptozotocin-induced diabetic rats. J Diabetes Metab Disord. 2011;10:3.

Ojo O, Kabutu F, Bello M, Babayo U. Inhibition of paracetamolinduced oxidative stress in rats by extracts of lemongrass (Cymbropogon citratus) and green tea (Camellia sinensis) in rats. Afr J Biotechnol. 2006;5(12):1227-1232.

Rakhshandehroo M, Knoch B, Müller M, Kersten S. Peroxisome proliferator-activated receptor alpha target genes. PPAR Res. 2010;2010:612089.

Reddy JK. III. Peroxisomal $\beta$-oxidation, $\operatorname{PPAR} \alpha$, and steatohepatitis. Am J Physiol Gastrointest Liver Physiol. 2001;281(6):G1333-G1339.

Saravanan G, Ponmurugan P, Deepa MA, Senthilkumar B. Antiobesity action of gingerol: effect on lipid profile, insulin, leptin, amylase and lipase in male obese rats induced by a high-fat diet. J Sci Food Agric. 2014;94(14):2972-2977.

Seren S, Mutchnick M, Hutchinson D, Harmanci O, Bayraktar Y, Mutchnick S, et al. Potential role of lycopene in the treatment of hepatitis $\mathrm{C}$ and prevention of hepatocellular carcinoma. Nutr Cancer. 2008;60(6):729-735.

Song Y, Zhao H, Liu J, Fang C, Miao R. Effects of citral on lipopolysaccharide-induced inflammation in human umbilical vein endothelial cells. Inflammation. 2016;39(2):663-671.

Souza-Mello V. Peroxisome proliferator-activated receptors as targets to treat non-alcoholic fatty liver disease. World J Hepatol. 2015;7(8):1012-1019.

Sreekumar R, Unnikrishnan J, Fu A, Nygren J, Short K, Schimke $\mathrm{J}$, et al. Impact of high-fat diet and antioxidant supplement on mitochondrial functions and gene transcripts in rat muscle. Am J Physiol Endocrinol Metab. 2002;282(5):E1055-E1061. 
Stanton MC, Chen S-C, Jackson JV, Rojas-Triana A, Kinsley $\mathrm{D}$, Cui L, et al. Inflammatory signals shift from adipose to liver during high fat feeding and influence the development of steatohepatitis in mice. J Inflamm. 2011;8(1):1-14.

Videla LA, Rodrigo R, Araya J, Poniachik J. Insulin resistance and oxidative stress interdependency in non-alcoholic fatty liver disease. Trends Mol Med. 2006;12(12):555-558.

Yang Q, Graham TE, Mody N, Preitner F, Peroni OD, Zabolotny JM, Kotani K, Quadro L, Kahn BB. Serum retinol binding protein 4 contributes to insulin resistance in obesity and type 2 diabetes. Nature. 2005;436(7049):356-362.

Yang Q, Graham TE, Mody N, Preitner F, Peroni OD, Zabolotny JM, et al. Citral is renoprotective for focal segmental glomerulosclerosis by inhibiting oxidative stress and apoptosis and activating Nrf2 pathway in mice. PloS One. 2013;8(9):e74871.

Zahran WE, El-Dien KAS, Kamel PG, El-Sawaby AS. Efficacy of tumor necrosis factor and interleukin-10 analysis in the follow-up of nonalcoholic fatty liver disease progression. Indian J Clin Biochem. 2013;28(2):141-146.
Zammit VA. Insulin Stimulation of Hepatic Triacylglycerol Secretion in the Insulin-Replete State. Ann N Y Acad Sci. 2002;967(1):52-65.

Ziamajidi N, Khaghani S, Hassanzadeh G, Vardasbi S, Ahmadian S, Nowrouzi A, et al. Amelioration by chicory seed extract of diabetes-and oleic acid-induced non-alcoholic fatty liver disease (NAFLD)/non-alcoholic steatohepatitis (NASH) via modulation of PPAR $\alpha$ and SREBP-1. Food Chem Toxicol. 2013;58:198-209.

Zou Y, Li J, Lu C, Wang J, Ge J, Huang Y, et al. High-fat emulsion-induced rat model of nonalcoholic steatohepatitis. Life Sci. 2006;79(11):1100-1107.

Received for publication on $03^{\text {rd }}$ October 2017 Accepted for publication on $28^{\text {th }}$ December 2017 